\title{
Temporary Hearing Loss and Associated Factors Among Ayka Addis Textile Factory Workers in Oromia Region, Ethiopia: A Cross-Sectional Study
}

This article was published in the following Dove Press journal: Risk Management and Healthcare Policy

\author{
Yonas Angaw (D) \\ Abera Kumie ${ }^{2}$ \\ Yifokire Tefera $\mathbb{D}^{2}$ \\ Samson Wakuma ${ }^{2}$ \\ Ansha Nega ${ }^{2}$ \\ Hagos Degefa Hidru (D) \\ Medhin Mehari $\mathbb{D}^{\prime}$ \\ Embay Amare Alemseged (1D) \\ Abadi Hailay (1D) \\ Fre Gebremeskel ${ }^{\prime}$ \\ Haftom Mamo (D) $^{3}$ \\ Hailu Belay ${ }^{3}$ \\ Meresa Berwo Mengesha ${ }^{4}$ \\ Hirut Teame $\left.{ }^{\prime}\right)^{\prime}$ \\ 'College of Medicine and Health Science, \\ Department of Public Health, Adigrat \\ University, Adigrat, Ethiopia; ${ }^{2}$ College of \\ Health Science, Department of Public \\ Health, Addis Ababa University, Addis \\ Ababa, Ethiopia; ${ }^{3}$ College of Medicine and \\ Health Science, Department of \\ Psychiatry, Adigrat University, Adigrat, \\ Ethiopia; ${ }^{4}$ College of Medicine and Health \\ Science, Department of Midwifery, \\ Adigrat University, Adigrat, Ethiopia
}

Correspondence: Yonas Angaw Email yonasangaw27@gmail.com
Introduction: The development of modern automated machines in industries has considerably decreased the physical burden of workers in addition to increasing the productivity of the industries resulting in noise pollution. Noise exposure above the limit value of $90 \mathrm{~dB}(\mathrm{~A})$ is known to cause temporary hearing loss among exposed workers.

Materials and Methods: Institutional-based cross-sectional study design was employed for a total of 406 study participants using a simple random sampling technique from January 15 to April 30, 2019. The data collection methods were observational checklist and a selfadministered questionnaire. The collected data were entered into EpiData software version 4.2 and exported to SPSS software version 21 for analysis. Bivariate and multivariable logistic analyses wwere used to identify the associated factors. Statistical significance was declared using a 95\% confidence interval and $a p$-value of less than 0.05 .

Results: A total of 388 study participants were included in the study with a response rate of $95.6 \%$, of which $254(65.5 \%)$ were females. The overall temporary hearing loss among the textile factory workers was found to be $49 \%$ with $\mathrm{COR}=1.53$; 95\% CI (1.15-2.03). The workers from the spinning department were 2.38 times more likely to develop temporary hearing loss after exiting from work than workers from the dyeing department $(95 \% \mathrm{CI}=$ (1.16-4.90). Similarly, workers from the knitting department were 3.67 times more likely to develop temporary hearing loss after exiting from work than workers from the dyeing department (95\% CI=1.42-9.47).

Conclusion: The present study demonstrated that the workforce in the spinning and knitting departments of the textile factory had a high prevalence of temporary hearing loss than the workers in dyeing and garment working sections. Therefore, the textile factory should provide hearing protection devices to the workers.

Keywords: noise exposure, temporary hearing loss, Ayka Addis

\section{Background}

The development of modern automated machines in industries has considerably decreased the physical burden of workers in addition to increasing the productivity of the industries. However, one of the most undesirable and unavoidable by-products of these operations and machines is noise-pollution. ${ }^{1}$ Noise is an unwanted sound that exposure to a high level can lead to temporary hearing loss among workers. ${ }^{2}$

Noise exposure is defined as "the environmental disturbance caused by noise or noise resulting in feeling unrested for living in the vicinity and is one of the most widespread occupational and environmental hazards in the world. ${ }^{3}$ Average noise exposures $>90$ Decibel A ( $\mathrm{dBA})$ have been linked to a variety of adverse auditory 
effects including noise-induced temporary hearing loss, which may interfere with workers' ability to hear warning signals or monitor workplace equipment. ${ }^{4}$

Noise can also exceed the attenuation rating of the Hearing Protective Devices (HPDs), can be transferred via air leaks, or can be transmitted via bone conduction through mechanical stimulation of the skull. ${ }^{5}$ Health effects of noise on individuals depending on the level of noise, individual susceptibility, duration of exposure, availability of HPDs, and awareness on the use of these HPDs. Exposure duration of 40 hours per week of equivalent noise level $<90 \mathrm{~dB}$ (A) is considered to be safe and noise level above this limit is bound to cause noise-induced hearing impairment such as temporary hearing loss. ${ }^{6}$ In Ethiopia also exposure to noise with respected time or hours is sated with the Ethiopia occupational safety and health directives as to the following: $90 \mathrm{dBA}$ for $8 \mathrm{hrs}, 92 \mathrm{dBA}$ for $6 \mathrm{hrs}, 95 \mathrm{dBA}$ for $4 \mathrm{hrs}$, $97 \mathrm{~dB}$ A for $3 \mathrm{hrs}, 100 \mathrm{~dB}$ A for $2 \mathrm{hrs}, 102 \mathrm{~dB}$ A for 1 and $1 / 2$ hrs., 105dBA for $1 \mathrm{hr}, 110 \mathrm{dBA}$ for $1 / 2$ an hr and $115 \mathrm{~dB}$ A for $1 / 4 \mathrm{hr}$.

Temporary hearing loss is when the hearing level can be produced by brief exposure to high-level sound and recovered after resting time. It is also a threshold shift that recovers to pre-exposure or baseline levels in the hours, days, or weeks following exposure to high noise levels. It is also related to ringing trouble of ears and day to day interference to normal conversations of the exposed workers. ${ }^{7}$ However, noise-induced temporary hearing loss produced by 10 years of daily exposure is approximately equal to the temporary threshold shift produced by the same noise level after an 8-hour exposure. Development of therapeutics that can reduce or prevent Noise-Induced Hearing Loss (NIHL) is a goal for many research teams, and temporary hearing loss study designs have been the primary model to date for evaluating proposed otoprotective agents in humans. ${ }^{5}$

Ethiopia is one of the developing countries which introduces different industrial settings and offers one of the largest domestic markets in Africa in terms of textile factory products, given its population size and rapid economic growth. Although dangerous noise levels have been previously measured in Ethiopian factories, only one study has documented specifically about noise-induced hearing loss and workers' awareness of the utilization of hearing protective devices.

The rationale for temporary hearing loss assessment is largely based on the assumption that demonstrating reduction of temporary hearing loss provides proof of concept for potential protection against permanent hearing loss; that is, it has some predictive value. Most agents shown to reduce temporary hearing loss have also been shown to reduce permanent hearing loss, although some other agents that reduce temporary hearing loss have had less consistent effects in temporary hearing models. ${ }^{8}$ Thus, this study was designed to assess temporary hearing loss and associated factors among the Ayka Addis textile factory workers.

\section{Materials and Methods \\ Study Area and Period}

The study was conducted in Ayka Addis textile factory (12 km from the center of Addis Ababa, capital of the country), the Ethiopian subsidiary of the Turkish textile which was inaugurated in 2010 for US\$140 million at Sebeta (Alemgena). The textile factory includes 4157 production section workers. The textile factory has four production departments/sections such as spinning, knitting, dyeing, and garment. The study was conducted from January 15 to April 30, 2019.

\section{Study Design}

The institutional-based cross-sectional study design was employed.

\section{Source Population}

All employees working and involved in different production activities at Ayka Addis textile factory was used as a source population.

\section{Study Population}

Employees who were working in Ayka Addis textile factory and satisfied the inclusion criteria were study subjects.

\section{Eligibility Criteria's}

Inclusion Criteria

Workers with at least one year of service in different production sections of the textile factory were included irrespective of sex and age.

\section{Exclusion Criteria}

Workers who had any type of noise-induced hearing loss (deafness), permanent hearing problem and seriously ill (head injury, other severe illnesses)

\section{Sample Size Determination and Sampling Technique}

Single population proportion formula was used to determine the sample size, assuming the prevalence of temporary hearing loss $40 \%,{ }^{9} 95 \%$ confidence interval, $5 \%$ margin of error with a $10 \%$ non-response rate. 406 subjects were taken as 
a final sample size for this study. A list of individuals from the attendance in the study factory was used as a sampling frame and the sample was distributed based on probability proportion to size (PPS) allocation method to each production section based on the total number of workers per each production department. Then, the respondents were selected using a simple random sampling technique (Figure 1).

\section{Data Collection Procedures Self-Administered Questionnaire}

A standard questionnaire was developed from the literature of a similar study to assess noise exposure and temporary hearing loss in the textile factory. Since educational level (grade 8-10) is a criterion for hiring workers in the textile factory, a self-administered questionnaire translated to local language (Affan Oromifa) was used to assess workers' reflection on temporary hearing loss. With close monitoring, the questionnaire was distributed to the selected workers within 2 up to 5 minutes after they accomplish their job or end of noise exposure to identify the real temporary hearing loss that can be caused by noise exposure in the textile factory.

\section{Observational Checklist}

An observational checklist was used to assess the institutions' setup regarding noise control measures such as engineering control and the availability of hearing protective devices. The training status of workers and practices related to occupational health and safety regarding noise hazards was also assessed using the prepared checklist.

\section{Aerial Noise Exposure Level Measurement}

An aerial noise survey was performed to assess the general noise exposure level of workers in each working department of the textile factory. Bruel \& Kjaer 4448 Personal Dsimeter (Denmark brand) (Figure 2) was used to measure the noise levels in the departments. During the aerial preliminary survey, every 2-meter square, there was a recording of noise level for 5 minutes, and the equipment was held $1.5 \mathrm{~m}$ above the floor in every production section of the textile factory. The measurement was performed for 8 hours in each department to identify the exact working time noise exposure of workers in the textile factory. And then the data from the personal dosimeter was transformed into a personal computer using Protector Type 7825 software. Even though Sound Level Measurement (SLM) was recommended to be used for aerial noise level measurement, a personal dosimeter (Bruel \& Kjaer 4448) was used to measure aerial noise level in the absence of Sound Level Meter (SLM).

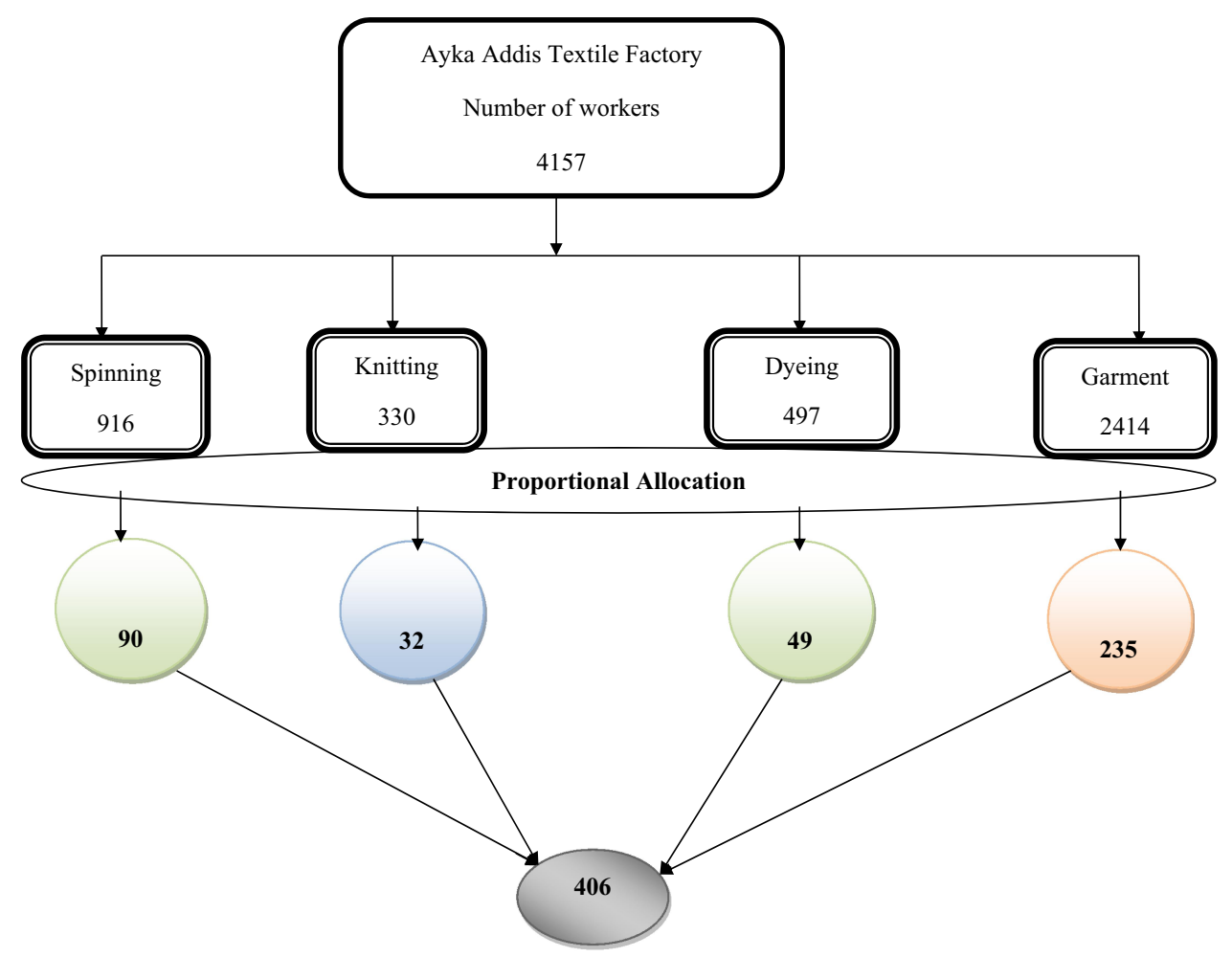

Figure I Schematic presentation of sampling techniques for different work sections in the textile factory, 2019. 

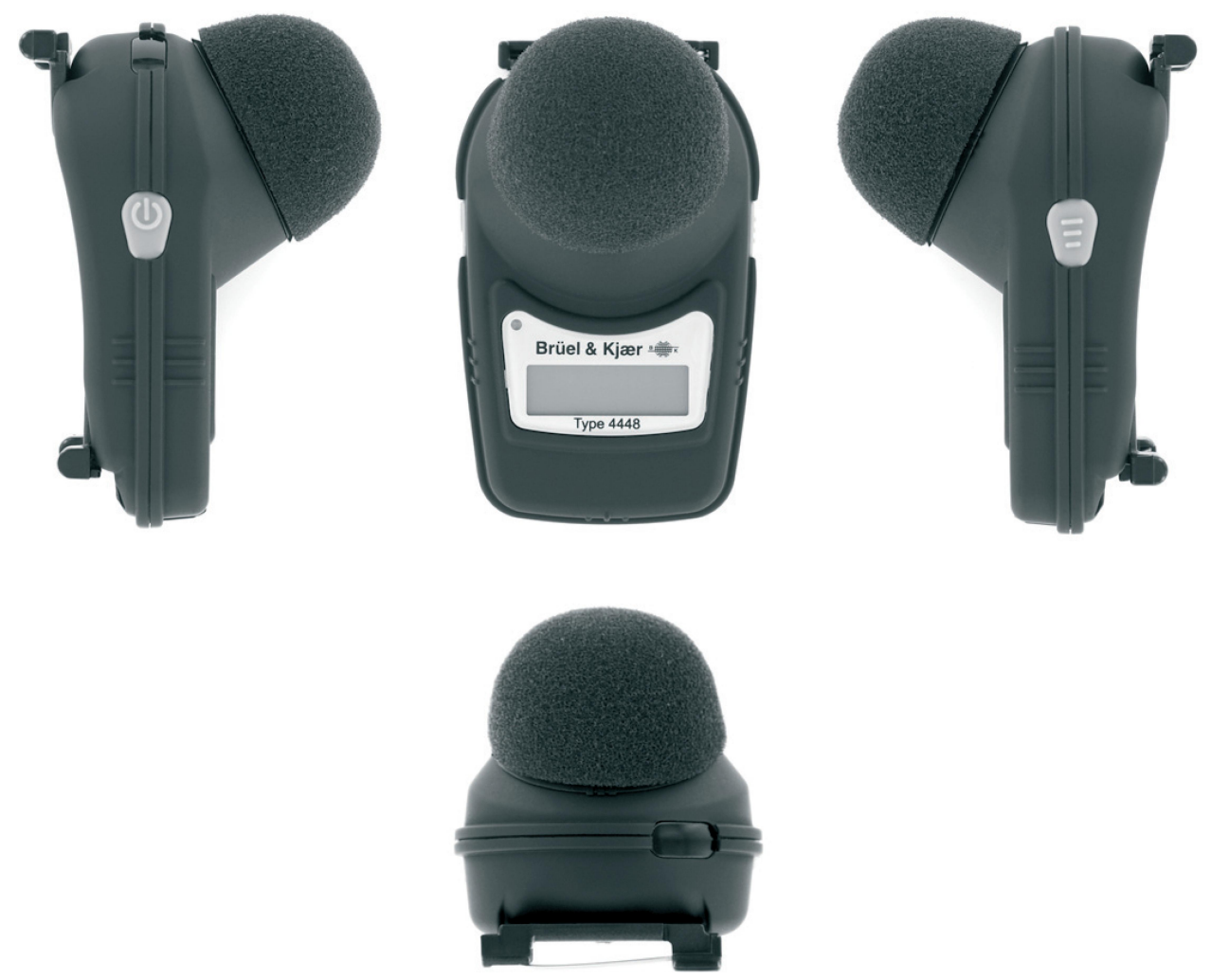

Figure 2 Personal dosimeter type 4448 (Denmark brand) used for aerial noise level measurement.

\section{Data Processing and Analysis}

Data were collected by trained environmental health professionals, using a structured pre-tested questionnaire and observational checklist reviewed from related articles. Data were coded, cleaned, checked, and corrected for errors and entered into EpiData version 4.2 and then exported to SPSS version 21 for analysis.

Bivariate logistic regression analysis was done for each variable and variables with their $\mathrm{p}$-value $<0.2$ were taken to the Multivariable analysis. The odds ratio was computed to show the strength of the association between the dependent variable and the explanatory variables. Statistical significance tests were assured using odds ratios with a p-value of $<0.05$ and a confidence interval of $95 \%$.

\section{Operational Definitions}

Exposure duration/time: Is the length of hours that a worker is exposed to any noise level during work time. ${ }^{6}$

Noise: is an excessive or unwanted sound that potentially results in annoyance and/or hearing loss. ${ }^{10}$

Permanent threshold shift: Noise-induced threshold shift that persists after a period of recovery after the exposure; at least 3 weeks recovery time. ${ }^{7}$
Temporary hearing loss: It is a change in the hearing threshold that recovers to pre-exposure levels or baseline over time; the amount of time to recover to baseline may be relatively fast (minutes to hours) or slow (day to weeks). ${ }^{7}$

\section{Results}

\section{Socio-Demographic Characteristics}

A total of 388 study participants were included in the study with a response rate of $95.6 \%$. Respondents' ages ranged from 18 to 49 years, with Mean $( \pm \mathrm{SD}) 25.5( \pm 4.95)$ years. Besides, all participants have attained education from primary school to higher education levels, in which 176 (45.4\%) were grade 9-10 and 158 940.7\%) were at the diploma level and concerning to marital status more than half, $244(62.9 \%)$ of the participants were single (Table 1).

\section{Work-Related Factors Among the Textile Factory Workers}

Out of 388 participants, 14 (3.6\%) employees in the textile factory were working in other noisy jobs (Flour mills, Garages, and cement factories) before they were started a job at this factory. Smoking was not common in the textile factory, in which only $2(0.5 \%)$ individuals were smokers among the 
Table I Socio-Demographic Characteristics of Ayka Addis Textile Factory Workers, Oromia Region, 2019

\begin{tabular}{|c|c|c|}
\hline $\begin{array}{l}\text { Variables } \\
(n=388)\end{array}$ & $\begin{array}{l}\text { Textile Factory Workers, } \\
\text { n (\%) }\end{array}$ & P-value \\
\hline \multicolumn{3}{|l|}{ Sex } \\
\hline Male & I34 (34.5) & 0.13 \\
\hline Female & $254(65.5)$ & \\
\hline \multicolumn{3}{|l|}{ Age (in years) } \\
\hline $18-28$ & $313(86.6)$ & 0.12 \\
\hline $29-39$ & $76(13.4)$ & \\
\hline $40-50$ & 8 & \\
\hline Mean \pm SD & $25.5 \pm 4.9$ & 0.26 \\
\hline \multicolumn{3}{|l|}{ Marital status } \\
\hline Single & $244(62.9)$ & \\
\hline Married & $122(3 \mid .4)$ & 0.23 \\
\hline Divorced & $5(1.3)$ & \\
\hline Widowed & $17(4.4)$ & \\
\hline \multicolumn{3}{|l|}{ Educational status } \\
\hline I-8 & $10(2.6)$ & \\
\hline $9-10$ & $176(45.4)$ & 0.15 \\
\hline Diploma & $158(40.7)$ & \\
\hline Degree & 44 (II.3) & \\
\hline \multicolumn{3}{|l|}{ Monthly income } \\
\hline$\leq 2500$ ETB & $283(73)$ & 0.5 \\
\hline$>2500$ ETB & $105(27)$ & \\
\hline
\end{tabular}

respondents. Similarly, there were only $32(8.2 \%)$ respondents who had the habit of alcohol drink in the textile factory. Regards to work experience, 317 (81.7\%) participants had a work experience of $1-5$ years and 71 (18.3\%) workers had service years of greater than 5 years. The majority of the workers had a working time of 8 hours per day in which there was no overtime work system, but 170 (43.8\%) employees from departments of spinning, knitting, and dyeing had a working time of greater than 40 hours per week. In addition to this, $122(31.4 \%)$ workers were engaged in relatively high noise level departments such as spinning and knitting. The work shift schedule in the textile factory was every week/ weekly in all production sections. But, workers in the garment department have five working days per week and also no shift schedule among the workers (office hour workers).

The minority of the textile factory workers, $20(5.2 \%)$, and $5(1.3 \%)$ participants respectively had a severe head injury and ear drain problems before they were started a job at the factory. Though, $40(10.3 \%)$ workers reported that there was disturbing noise around their residents from road traffic, mills, and religious institutions. Besides, 24 $(6.2 \%)$ workers have complained of or the presence of
Table 2 Work-Related Factors Among Ayka Addis Textile Factory Workers, Oromia, 2019

\begin{tabular}{|c|c|c|}
\hline Variables $(n=388)$ & $\begin{array}{l}\text { Textile Factory Workers, } \\
\text { n (\%) }\end{array}$ & P-value \\
\hline $\begin{array}{l}\text { Working departments } \\
\text { Spinning } \\
\text { Knitting } \\
\text { Dyeing } \\
\text { Garment }\end{array}$ & $\begin{array}{l}90(23.2) \\
32(8.2) \\
48(12.4) \\
218(56.2)\end{array}$ & 0.04 \\
\hline $\begin{array}{l}\text { Work experience } \\
\text { I-5 years } \\
>5 \text { years }\end{array}$ & $\begin{array}{l}317(81.7) \\
71(18.3)\end{array}$ & 0.15 \\
\hline $\begin{array}{l}\text { Working hours per week } \\
\leq 40 \mathrm{hrs} \text {. } \\
>40 \mathrm{hrs} \text {. }\end{array}$ & $\begin{array}{l}218(56.2) \\
170(43.8)\end{array}$ & 0.02 \\
\hline $\begin{array}{l}\text { Head injury } \\
\text { Yes } \\
\text { No }\end{array}$ & $\begin{array}{l}20(5.2) \\
368(94.8)\end{array}$ & 0.03 \\
\hline $\begin{array}{l}\text { Ear drain } \\
\text { Yes } \\
\text { No }\end{array}$ & $\begin{array}{l}5(1.3) \\
383(98.7)\end{array}$ & 0.26 \\
\hline $\begin{array}{l}\text { Worked at noisy jobs } \\
\text { Yes } \\
\text { No }\end{array}$ & $\begin{array}{l}\text { I4 (3.6) } \\
374(96.4)\end{array}$ & 0.22 \\
\hline $\begin{array}{l}\text { Hx of Ear infection } \\
\text { Yes } \\
\text { No }\end{array}$ & $\begin{array}{l}34(8.8) \\
354(91.2)\end{array}$ & 0.20 \\
\hline $\begin{array}{l}\text { Medication } \\
\text { Yes } \\
\text { No }\end{array}$ & $\begin{array}{l}23(5.9) \\
365(94.1)\end{array}$ & 0.21 \\
\hline
\end{tabular}

severe headaches confirmed by Physicians before they have started a job at this textile factory (Table 2).

\section{Prevalence of Temporary Hearing Loss Among Workers}

The overall temporary hearing loss among the textile factory workers was found to be $49 \%$ with $(\mathrm{COR}=1.53 ; 95 \% \mathrm{CI}=$ (1.15-2.03). The workers from the spinning department were 2.38 times more likely to develop temporary hearing loss after exiting from work than workers from the dyeing department $(95 \% \mathrm{CI}=(1.16-4.90)$. Similarly, workers from the knitting department were 3.67 times more likely to develop temporary hearing loss after exiting from work than workers from the dyeing department $(95 \% \mathrm{CI}=1.42-9.47)$. Regarding trouble noise around the ear, spinning workers had 2.17 times more likely to develop the problem than dyeing workers with 
(95\% CI=1.06-4.44). In addition to this, the workers from the spinning department were 3.6 times more likely to suffer from trouble noise around the ear than workers from the garment department $(95 \% \mathrm{CI}=2.14-6.03)$. In addition to the above associations, the difference in the different symptoms of temporary hearing loss such as difficulty in communication with friends after work, difficulty in phone call conversation, and the problem of normal communication during work time was statistically significant among workers from different textile factory departments (Table 3).

Table 3 Prevalence of Temporary Hearing Loss in Ayka Addis Textile Factory Workers, Oromia, 2019

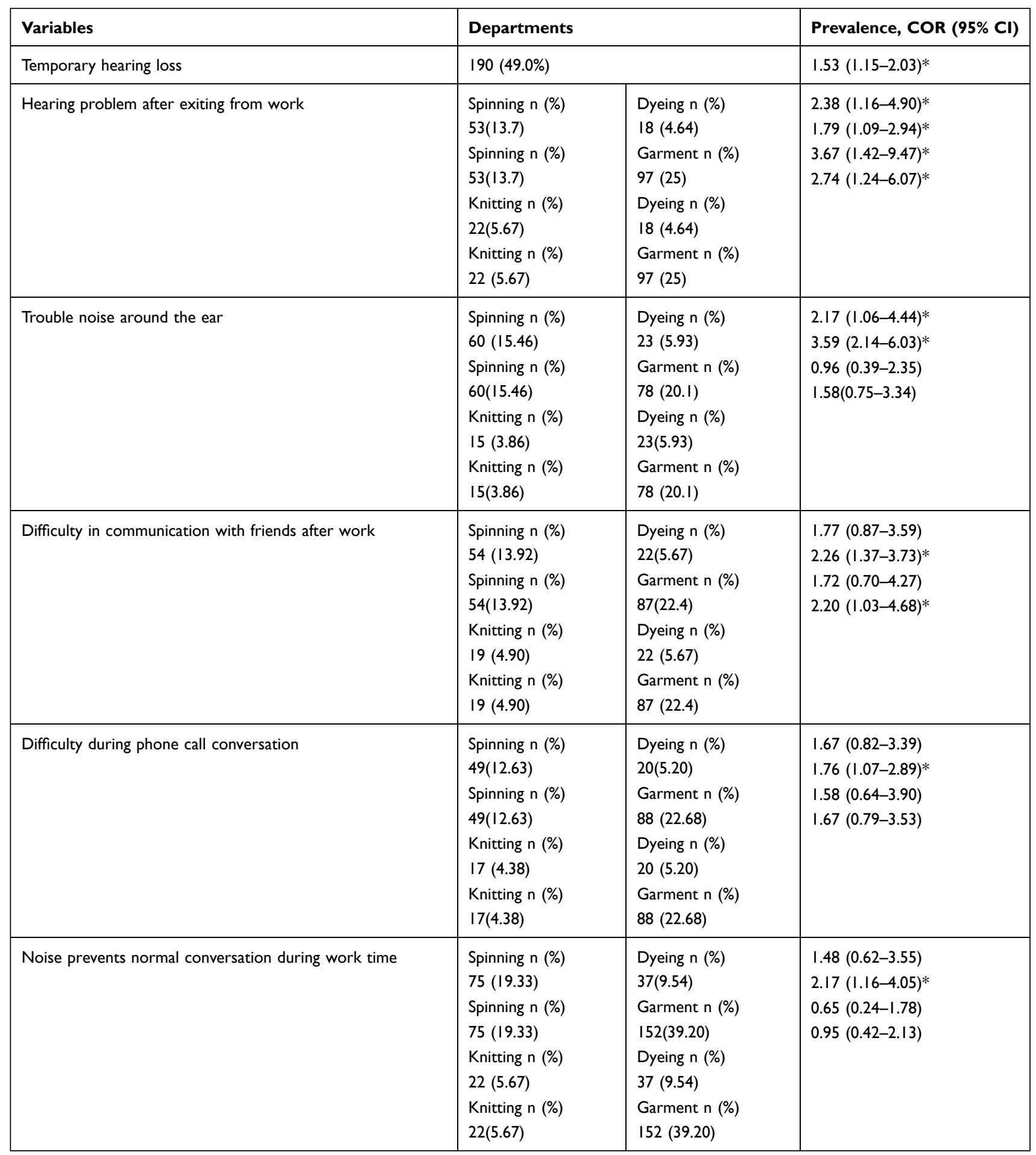

Note: $* \mathrm{P} \leq 0.05$ for $\mathrm{COR}$.

Abbreviations: $\mathrm{COR}$, crude odds ratio; $\mathrm{Cl}$, confidence interval. 


\section{Associated Factors and Temporary Hearing Loss}

Working departments were significantly associated with temporary hearing loss among the textile factory workers. Workers who were engaged in the spinning department were 3.55 times more likely to develop temporary hearing loss than workers engaged in the garment section $(95 \%$ $\mathrm{CI}=1.72-7.32$ ), workers who were working in the knitting section were 2.48 times more likely to develop temporary hearing loss than workers engaged in the garment department (95\% CI=1.46-4.21). Similarly, workers who work greater than 40 hours per week in the factory were 2.1times more likely to develop temporary hearing loss than workers who had 40 hours or less per week $(95 \% \mathrm{CI}=1.18-3.70)$ which was found statistically significant factors (Table 4). In addition to the above-associated factors, none of the textile factory workers have used hearing protective devices. The main reasons mentioned by the participants for none use of hearing protective devices were; 342 (88.2\%) reported lack of availability/

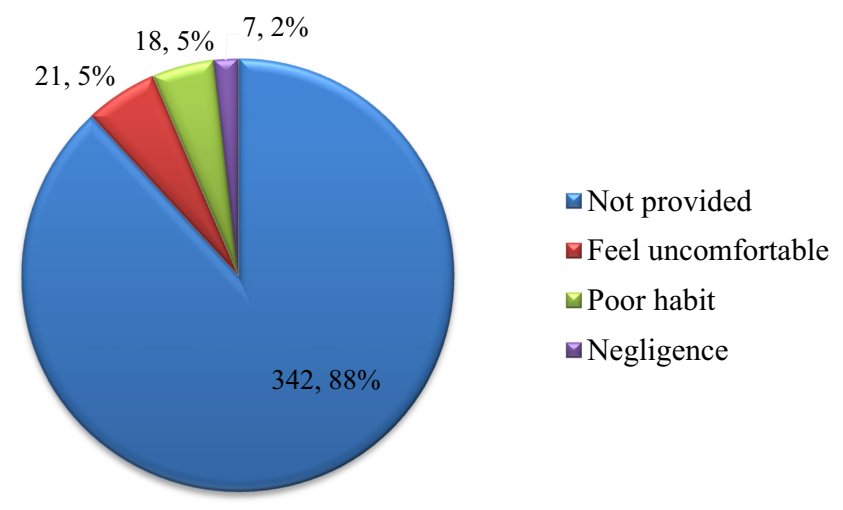

Figure 3 Reasons for not use of hearing protective devices among Ayka Addis textile factory workers, Oromia $2019(n=388)$.

not provided by the factory and $21(5.4 \%)$ feel uncomfortable using those hearing protective devices (Figure 3 ).

\section{Workplace Observation}

Workplace observation of the study showed that no engineering control was applied to reduce the noise level

Table 4 Temporary Hearing Loss and Associated Factors Among Ayka Addis Textile Factory Workers, Oromia, 2019

\begin{tabular}{|c|c|c|c|c|}
\hline \multirow[t]{2}{*}{ Variables } & \multicolumn{2}{|c|}{ Temporary Hearing Loss } & \multirow[t]{2}{*}{ COR $(95 \% \mathrm{Cl})$} & \multirow[t]{2}{*}{ AOR (95\% Cl) } \\
\hline & Yes & No & & \\
\hline \multicolumn{5}{|l|}{ Sex } \\
\hline Male & 57 & 77 & $0.90(0.60-1.39)$ & $0.69(0.30-1.57)$ \\
\hline Female & 114 & 140 & 1.00 & 1.00 \\
\hline \multicolumn{5}{|l|}{ Age (in years) } \\
\hline $18-28$ & 138 & 175 & 1.00 & 1.00 \\
\hline $29-39$ & 39 & 37 & $0.97(0.57-1.65)$ & $0.99(0.48-2.00)$ \\
\hline $40-50$ & 3 & 5 & $1.31(0.31-5.60)$ & $1.17(0.70-1.90)$ \\
\hline \multicolumn{5}{|l|}{ Educational status } \\
\hline $\mathrm{I}-8$ & 4 & 6 & $0.88(0.22-3.55)$ & $0.9(0.40-2.00)$ \\
\hline $9-10$ & 78 & 98 & $1.05(0.54-2.04)$ & $1.02(0.43-2.45)$ \\
\hline Diploma & 70 & 88 & $1.05(0.54-2.05)$ & $1.08(0.50-2.20)$ \\
\hline Degree & 19 & 25 & 1.00 & 1.00 \\
\hline \multicolumn{5}{|l|}{ Working departments } \\
\hline Spinning & 53 & 37 & $1.79(1.09-2.94)^{*}$ & $3.55(1.72-7.32)^{* *}$ \\
\hline Knitting & 22 & 10 & $2.74(1.24-6.07)^{*}$ & $2.48(I .46-4.21)^{* *}$ \\
\hline Dyeing & 18 & 30 & $0.75(0.39-1.42)$ & I.10 (0.50-2.40) \\
\hline Garment & 97 & 121 & 1.00 & 1.00 \\
\hline \multicolumn{5}{|l|}{ Work experience } \\
\hline $\mathrm{I}-5$ years & 146 & 171 & 1.00 & 1.00 \\
\hline$>5$ years & 25 & 46 & $0.64(0.37-1.09)$ & $0.93(0.46-1.90)$ \\
\hline \multicolumn{5}{|l|}{ Working hrs./week } \\
\hline$\leq 40$ hours & 97 & 121 & 1.00 & 1.00 \\
\hline$>40$ hours & 93 & 77 & $1.5(1.01-2.25)^{*}$ & $2.19(1.18-3.70) * *$ \\
\hline
\end{tabular}

Notes: $1.00=$ reference value, $R^{2}=0.823, * P \leq 0.2$ for $C O R$ and $* * P \leq 0.05$ for $A O R$. 
released from the machines. Regarding personal protective equipment, no individual was using a hearing protective device during work time due to the lack of availability of the equipment in the textile factory. The other observation regarding the noise level was indicated that noise levels in the spinning and knitting were very disturbing and high than that of dyeing and garment departments. Finally, areas with a high noise level in the textile factory were not labeled to keep workers safe from exposing themselves to impulsive noise levels from different machines.

\section{Aerial Noise Exposure Level in the Working Departments}

According to the Ethiopian directives agency, there are action limits and exposure limit value for workers. For the lower action limit ( $80 \mathrm{dBA})$ there should be information and training to workers and for the upper action limit ( $85 \mathrm{dBA})$ hearing protective devices required in the work setting. Besides, for exposure limit value of $87 \mathrm{dBA}$, there should be hearing protective devices and must not be exceeded to this limit. Workers were exposed continuously to noise exposure levels for an entire eight-hour shift except during a single forty-five minutes meal break. The factory is in use for 24 hours, six days per week. The noise exposure level in the four working departments will be presented in the following table (Table 5).

\section{Discussion}

This study demonstrated that noise was a serious occupational health hazard in the textile factory. The level of temporary hearing loss among the textile workers, $49 \%$ were higher when compared to a study conducted in SivasTurkey among textile factory workers; which was $40 \%{ }^{9}$ This might be due to the textile factory setup, sample size difference, and control measures taken on noise exposure of workers. The higher level of temporary hearing loss in spinning department workers was due to a relatively high

Table 5 Aerial Noise Exposure Level of Different Production Departments in Ayka Addis Textile Factory, Oromia Region, 2019

\begin{tabular}{|l|l|l|l|l|}
\hline \multirow{2}{*}{ S. No } & \multirow{2}{*}{$\begin{array}{l}\text { Production } \\
\text { Depts. }\end{array}$} & \multicolumn{3}{|c|}{ Aerial Measurements (in dBA) } \\
\cline { 3 - 5 } & & Minimum & Maximum & LAeq, 8 \\
\hline 1 & Spinning & 78 & 115 & 108.2 \\
2 & Knitting & 68 & 113 & 109 \\
3 & Dyeing & 61 & 79 & 86.9 \\
4 & Garment & 48 & 78 & 74.4 \\
\hline
\end{tabular}

noise level than dyeing and garment departments. This might be due to exposure to eight-hour time for a relatively high noise level leads workers to have trouble noise around their ear/head for a long time after exiting from the workplace.

Besides, $44.85 \%$ of workers had difficulties in phone call conversations which was higher when compared to a study conducted among individuals in the United Arab Emirates (UAE) in which $14 \%$ of students had difficulty in hearing telephone conversations. ${ }^{11}$ This higher variation might be due to the unavailability of hearing protective devices, the approach of data collection, and institutional setup. In this study majority, about $73.7 \%$ of workers had complained about the interference of noise level in their day-to-day normal conversations with co-workers. This problem was approximately similar to a study conducted in two textile plants of Northern India in which $70 \%$ of workers reported noise as the major factor causing speech interference. ${ }^{1}$

The major risk factors for temporary hearing loss were the duration of exposure and the noise level. This relationship was similar to previous studies in India and the Republic of Korea. ${ }^{1,12}$

In these studies in areas of high noise level, the temporary hearing loss was high and workers who had exposed for a long working time were suffering this occupational problem than workers with less exposure time.

The personal protective equipment utilization behavior of the textile factory workers was low. However, the majority of the workers agreed on the importance of hearing protective devices for preventing themselves from high noise levels emitted from the machines, but the textile factory does not supply hearing protective devices for workers who were in line with the result of a study conducted in Ethiopia among Dire-Dawa textile factory workers. $^{13}$

\section{Limitation of the Study}

One of the limitations of the study was the use of selfadministered questionnaires to identify the magnitude of temporary hearing loss symptoms of workers in which it can lead to the overestimation of the problem. Besides, since the study was cross sectional it will not show the cause-effect relationship of the problem.

\section{Conclusion and Recommendations}

Generally, temporary hearing loss was found higher among spinning workers than dyeing and garment 
workers. The working department and length of working hours were the determinant factors for the occurrence of temporary hearing loss. None of the employees in the textile factory were provided hearing protective devices which is the last option for controlling and preventing noise exposures. In general, the results of this study concluded that workers working in the spinning and knitting production departments without using hearing protective devices were harmed the most. Since it is important to prevent workers from leaving their workplace due to different noise exposure-related health problems; our countries regulatory bodies have the opportunity to use this study as a starting point to assess what is happening in the textile factories of the country regarding workers health in general and specifically to noise-related health problems among the workers. Though, the textile factory should provide hearing protection devices to the workers to reduce the prevalence of this hearing problem. Besides, further studies should be conducted by including many types of textile factors and different study designs with audiometric measurements of the hearing capacity of workers.

\section{Abbreviations}

AOR, Adjusted odds ratio; dB (A), A weighted decibel; COR, Crude odds ratio; ETB, Ethiopian Birr; HPDs, Hearing protective devices; SD, Standard deviation; SLM, Sound Level Meter; SPSS, Statistical package for social science; TTS. Temporary threshold shift.

\section{Data Sharing Statement}

The datasets used and/or analyzed during this study are available from the corresponding author on a responsible request.

\section{Ethical Approval and Consent to Participate}

The study was conducted following the declaration of Helsinki on human subjects. After the purpose, benefit and risk were briefed, written informed consent was obtained from the study participants. Ethical clearance was secured by Addis Ababa University Institutional Health Research Ethics Review Committee (IHRERC) and official permission was obtained from Ayka Addis Textile factory, Oromia Health Office, and the Municipal.

\section{Consent for Publication}

Not applicable.

\section{Acknowledgments}

We would like to acknowledge Addis Ababa University, College of Health Science for all its bits of help. Our grateful gratitude would also go to all the data collectors, supervisors, and study participants.

\section{Funding}

There was no funding for this study.

\section{Disclosure}

The authors report no conflicts of interest for this work.

\section{References}

1. Raman B. Evaluation of Occupational Environment in Two Textile Plants in Northern India with Specific Reference to Noise. 2006; 44:112-116.

2. Zerihun S, Mamo H, Sitotaw B, Mengistu E. Evaluation of the people perception of major noise sources and its impact on health at Dire-Dawa city, Ethiopia. Romanian J Biophys. 2017;27:69-78.

3. http://www.euro.who.int/_data/assets/pdf_file/0008/136466/e94888. pdf. Accessed February 27, 2015.

4. Cantley FL, Galusha D, Cullen MR, et al. Association between ambient noise exposure, hearing acuity, and risk of acute occupational injury. Scandinavian J Work Environ Health. 2015;41(1): 75-83.

5. Spankovich C, Lobariñas E, Morgenstein KE, et al. Temporary threshold shift after impulse-noise during video gameplay: Laboratory data. 2016.

6. American national institute of occupational health and safety 2006.

7. Ryan FA, Kujawa GS, Hammill T, Prell LC, Kil J. Temporary and permanent noise-induced threshold shifts: a review of basic and clinical observations. 2017.

8. Prell LG, Dell S, Hensley B, et al. Digital music exposure reliably induces temporary threshold shift (TTS) in normal-hearing human subjects. 2012.

9. Atmaca E, Peker I, Altin A. Industrial noise and its effects on humans. Pol J Environ Stud. 2005;14(6):721-726.

10. World Health Organization (WHO). Global Burden of Hearing Loss 2016.

11. Ahmed OH, Ali JA Noise Levels, Noise Annoyance and hearingrelated Problems in a Dental College. 2016.

12. Kim J, Lee W, Won J, et al. The relationship between occupational noise and vibration exposure and headache/eyestrain, based on the fourth Korean Working Condition Survey (KWCS). 2017.

13. Ayele B, Yemane B Noise-induced hearing loss among textile workers. 1995. 


\section{Publish your work in this journal}

Risk Management and Healthcare Policy is an international, peerreviewed, open access journal focusing on all aspects of public health, policy, and preventative measures to promote good health and improve morbidity and mortality in the population. The journal welcomes submitted papers covering original research, basic science, clinical \& epidemiological studies, reviews and evaluations, guidelines, expert opinion and commentary, case reports and extended reports. The manuscript management system is completely online and includes a very quick and fair peer-review system, which is all easy to use. Visit http://www.dovepress.com/testimonials.php to read real quotes from published authors. 